\title{
Technical Note: A containerized technique for studying root systems
}

\author{
RUSSELL K. ENGEL, JAMES T. NICHOLS, AND JOE E. BRUMMER
}

Authors are research technologist, professor of agronomy, and research coordinator, University of Nebraska, West Central Research and Extension Center, North Platte, Nebr. 69101.

\begin{abstract}
Quantifying root responses of naturally growing range plants to treatments is difficult. The objective of this study was to develop a containerized technique to study individual plants growing in the field under near natural environmental conditions. Three containers were evaluated: $15 \times 100 \mathrm{~cm}$ nylon $\left(2,000\right.$ pores $\left./ \mathrm{cm}^{2}\right)$ sacks, 15 $\times 100 \mathrm{~cm}$ polyvinyl chloride (PVC) tubes, and $30 \times 100 \mathrm{~cm}$ PVC tubes. The $15 \times 100 \mathrm{~cm}$ PVC tubes were easiest to handle, and plants grown in these containers appeared similar in size and growth form to adjacent, undisturbed plants. Survival rate for 165 sand bluestem (Andropogon hallii Hack.) plants grown for 2 years in the $15 \times 100 \mathrm{~cm}$ PVC tubes was $98.8 \%$. This survival rate was achieved despite clipping treatments during the second year.
\end{abstract}

Key Words: root/shoot study, Andropogon hallii, Calamovilfa longifolia

Studying root systems of individual range plants in their natural environment is difficult. Determining what constitutes an individual plant of a rhizomatous species is not easy, while the recovery and study of complete root systems is even more difficult. The importance of understanding root systems has long been recognized. Attempts to study root systems date back to the early 1700's (Troughton 1957, Bohm 1979).

Techniques that have been used to study the development and growth of roots in situ include: excavation, monoliths, auger or cores, profile walls, glass walls, tracers, and containers (Bohm 1979). Only the excavation and container techniques allow for recovery of complete, individual root systems. Excavation techniques such as the one described by Weaver (1954) are time consuming and become prohibitive when large numbers of samples are required.

Containerized techniques allow for the recovery of complete root systems and can facilitate taking a large number of samples. Materials used for containers have included: asbestos, cement, clay, wood, metal, glass, nylon, and plastic (Bohm 1979). Most containerized studies have been conducted in greenhouses under "optimum" conditions. A technique is needed which allows for the study of entire plants under near natural growing conditions. The technique should be easily employed to facilitate taking multiple replications and allow for plant survival and development.

The objective of this study was to develop a containerized technique to study individual plants growing in the field under near natural environmental conditions.

\section{Materials and Methods}

Two experiments were conducted at the Gudmundsen Sandhills

Published as Paper 10113, Journal Series, Nebraska Agriculture Research Division Manuscript accepted 26 Jan. 1993.
Laboratory near Whitman, Nebr., from 1988 through 1991 on a Valentine fine sand (mixed mesic Typic Ustipsamment). The study was located on a sands range site in excellent range condition. Vegetation of the study area included a mixture of tall-, mid-, and short-grass species. Sand bluestem (Andropogon hallii Hack.), prairie sandreed [Calamovilfa longifolia (Hook.) Scribn.], and little bluestem [Schizachyrium scoparium (Michx.) Nash] each contributed about $20 \%$ to above-ground dry matter production in the study area. Precipitation for the 4 growing seasons is shown in Table 1.

\section{Trial 1}

This trial was conducted in 1988 to determine which containers allowed for the survival and development of prairie sandreed and sand bluestem plants. Container sizes and materials included: $15 \times$ $100 \mathrm{~cm}$ nylon $\left(2,000\right.$ pores $\left./ \mathrm{cm}^{2}\right)$ sacks, $15 \times 100 \mathrm{~cm}$ polyvinyl chloride $(\mathrm{PVC})$ tubes, and $30 \times 100 \mathrm{~cm}$ PVC tubes.

Rhizomes with associated buds and roots were collected in mid-April by excavating at $15 \times 15 \times 25 \mathrm{~cm}$ block of soil around vegetative tillers produced the previous year. The excavated soil was sifted to remove other plant material and used for planting the rhizomes (with associated buds and roots) in $15-\mathrm{cm}$ diameter greenhouse pots. Plants were grown in the greenhouse for 3 weeks and then acclimatized in cold frames for 1 week. Most of the plants developed only 1 tiller while in the greenhouse. Secondary tillers that emerged were removed to standardize plant material prior to transplanting to containers in the field. Additional pruning was not

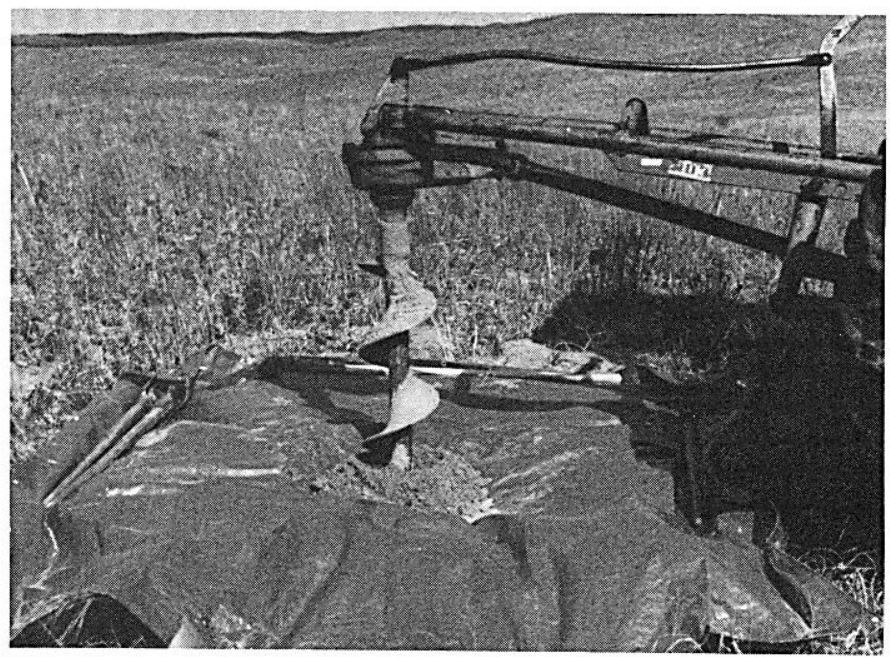

Fig. 1. Tractor-mounted auger used to drill holes to place containers in the ground. A tarp was used to collect soil for placement in containers and to minimize disturbance to the area. 
done after the plants were established in the containers.

Containers were arranged in a $1.5-\mathrm{m}$ grid and placed in the ground by drilling a hole the size of the container with a tractormounted auger (Fig. 1). All PVC tubes had a wooden plug at the bottom with holes covered with nylon to allow for water drainage and containment of root growth. Soil from the hole was collected on a tarp which was placed around the auger. The soil was hand sifted to remove plant material and placed inside the containers with near natural stratification. Plants were transferred (at the 2- to 3-leaf stage of growth) from the cold frames to the containers in the field during mid-May. Supplemental water was added at the time of transplanting. Five replications of the $15 \times 100 \mathrm{~cm}$ nylon sacks and PVC tubes were used for both sand bluestem and prairie sandreed. Five replications of the $30 \times 100 \mathrm{~cm}$ PVC tubes were used for sand bluestem.

\section{Trial 2}

Based on the results from Trial 1 , the $15 \times 100 \mathrm{~cm}$ PVC container was selected for further investigation with sand bluestem. For this trial, 88 and 77 sand bluestem plants were placed in containers during the spring of 1989 and 1990, respectively. Procedures used in trial 1 for establishing plants in the tubes were repeated for trial 2. Both sets of plants were allowed to grow for 1 year. During the second growing season, 12 replications (plants) were clipped to a 7 $\mathrm{cm}$ stubble height at mid-month for each of the following defoliation schedules: (1) June; (2) July; (3) August; (4) June and August; (5) June, July, and August; and (6) October. Survivability of containerized sand bluestem plants was determined under these clipping treatments.

Plants placed in containers in 1989 received small amounts of supplemental water 3 times during June of 1989. This was required due to inadequate precipitation (Table 1). Water was added when plants appeared stressed (wilted). Fenvalerate [Cyano(3-phenoxyphenyl)methyl-4-chloro-alpha-(1-methylethly) benzeneacetate] was applied (as needed) to control grasshoppers throughout the study.

Following the second growing season, tubes were removed from the ground. Hooks were attached to the top of the tubes and 2 people lifted them out of the ground. A plunger was used to hold
Table 1. Deviations from 30 year monthly averages of precipitation $(\mathrm{mm})$ from 1 May through 30 September for 1988 through 1991.

\begin{tabular}{|c|c|c|c|c|c|}
\hline Month & Average ${ }^{1}$ & 1988 & 1989 & 1990 & 1991 \\
\hline & \multicolumn{5}{|c|}{$\ldots-\ldots m m-\ldots$} \\
\hline May & 89 & +51 & -38 & +26 & +21 \\
\hline June & 92 & -03 & -65 & -38 & +51 \\
\hline July & 81 & -02 & -57 & +48 & -11 \\
\hline August & 60 & -29 & -25 & -11 & +31 \\
\hline September & 45 & -01 & -04 & -25 & +02 \\
\hline
\end{tabular}

${ }^{1}$ Owenby and Ezell (1992)

the soil columns in place as the tubes were pulled off with a hand winch (Fig. 2). This resulted in an intact soil column containing the entire root system which could then be washed free of soil for further evaluation.
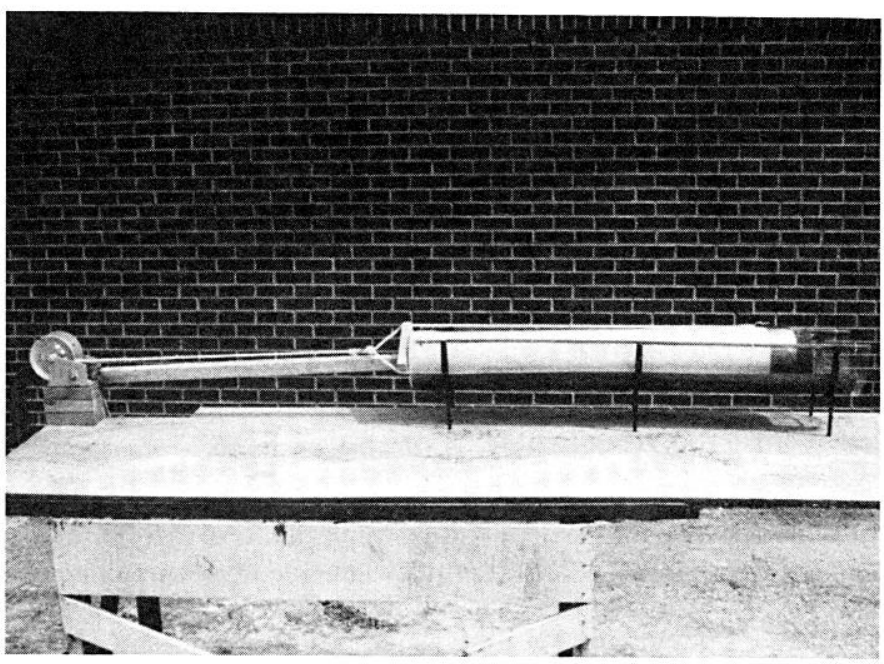

Fig. 2. Hand winch and plunger (between winch and soil column) used to pull PVC tubes from soil columns.

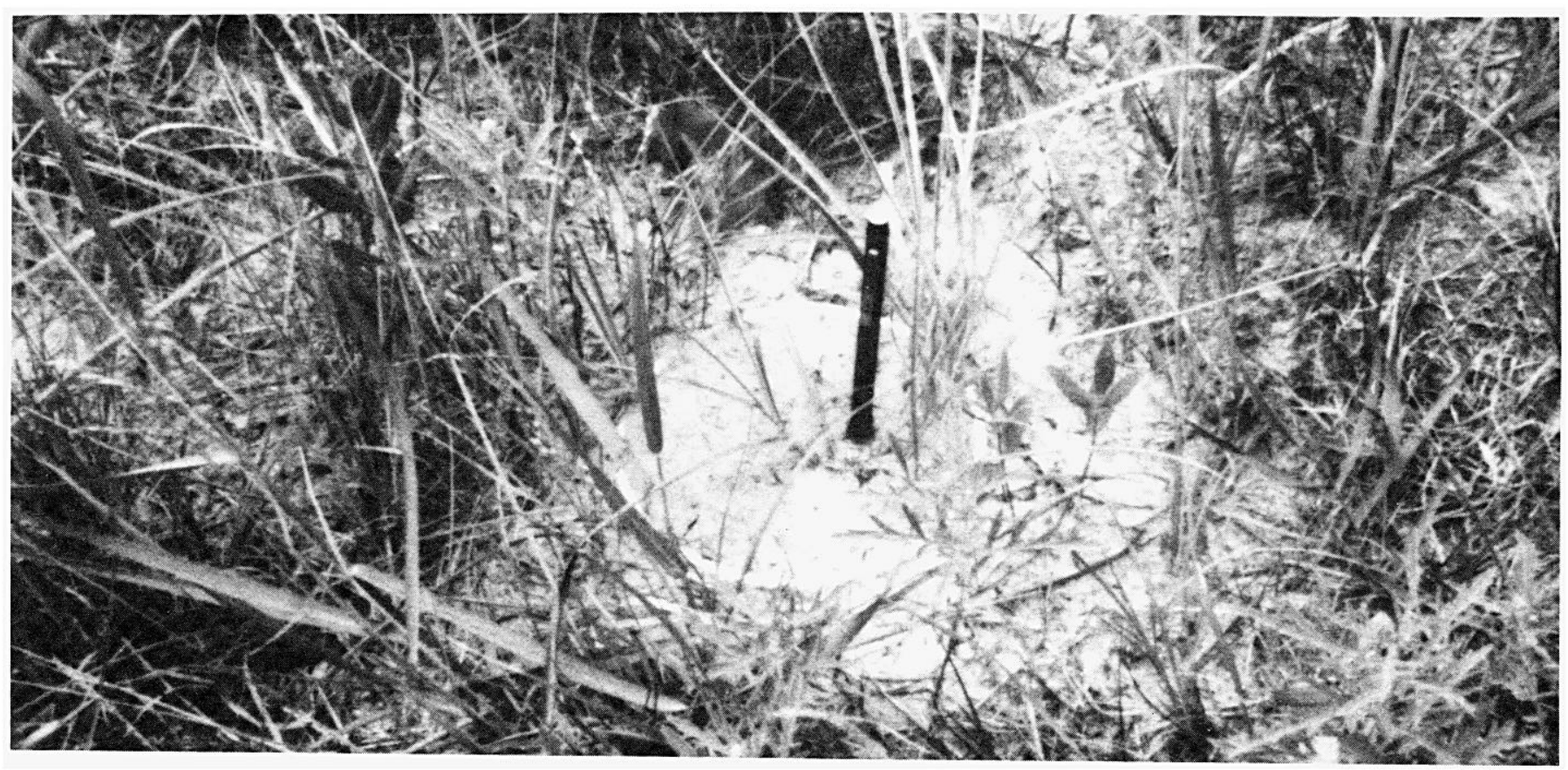

Fig. 3. Sand bluestem plant growing in a $15 \times 100 \mathrm{~cm}$ PVC tube showing similar size and growth form as the undisturbed surrounding plants. This technique also results in minimal site disturbance. 


\section{Results and Discussion}

\section{Trial 1}

Sixty percent of both sand bluestem and prairie sandreed plants grown in the $15 \times 100 \mathrm{~cm}$ nylon sacks survived the initial growing season. From visual observations, these plants appeared smaller than undisturbed "natural" plants growing in the vicinity.

All of the sand bluestem plants in the $30 \times 100 \mathrm{~cm}$ PVC tubes survived the initial growing season. These plants appeared larger and more robust than the natural plants. Two of these plants produced large reproductive culms during the first growing season.

Two of the sand bluestem plants grown in the $15 \times 100 \mathrm{~cm}$ PVC tubes were destroyed by grasshoppers. Seventy-five percent of the remaining sand bluestem and prairie sandreed plants survived the initial growing season. These plants appeared similar in size and growth form to the natural plants (Fig. 3).

This trial indicated that sand bluestem and prairie sandreed plants could survive in all 3 containers. Plants grown in the $15 \times$ $100 \mathrm{~cm}$ PVC tubes appeared more similar to adjacent, undisturbed plants in size and growth form than plants grown in either of the other 2 containers. In addition, these tubes could be pulled and handled manually, whereas the other 2 containers proved difficult to extract. Soil had to be removed from around the nylon sacks and the $30 \times 100 \mathrm{~cm}$ PVC tubes were heavy (approximately $125 \mathrm{~kg}$ ).

\section{Trial 2}

During the second trial, only sand bluestem and the $15 \times 100 \mathrm{~cm}$ PVC tubes were evaluated. An average of $98.8 \%(88 / 88$ in 1989 and $75 / 77$ in 1990) of plants survived the establishment year. One hundred percent of these plants survived the second year during which clipping treatments were imposed. To achieve this survivability rate, plants required small amounts of supplemental water during the spring of 1989 and the application of Fenvalerate to control grasshoppers. Throughout the trial, containerized plants appeared similar to the natural plants in size and growth form.

The $15 \times 100 \mathrm{~cm}$ PVC containers were easy to handle and reusable since they are not destroyed during extraction of the root system and will not deteriorate over time. This technique resulted in intact soil columns containing complete root systems which can be sectioned into depth increments. The capability then exists for detailed measurements to be taken on roots as well as shoots for each plant. With the aid of a computerized imaging machine (Harris and Campbell 1989), root length and area (2 dimensional) measurements can be easily obtained. Various other physical and chemical attributes of roots and shoots can be measured such as production, carbohydrate content, and mycorrhizal associations.

\section{Conclusion}

Sand bluestem and prairie sandreed plants survived and developed in all containers investigated in this study. Plants grown in the $15 \times 100 \mathrm{~cm}$ PVC tubes appeared similar to the adjacent, naturally growing plants in both size and growth form. These tubes were also easiest to handle and could be reused. This technique allowed for the isolation, recovery, and study of complete individual plants grown under near natural conditions. Detailed measurements of complete root systems as well as shoots can be taken with this technique. Due to the simplicity of the procedure, a large number of containers can be concentrated in a small area. This technique should be adaptable to a wide variety of plants and soil types, which would improve our ability to study entire plants and how they react to various treatments in different environments.

\section{Literature Cited}

Bohm, W. 1979. Methods of studying root systems. Springer-Verlag, N.Y. Harris, G.A., and G.S. Campbell. 1989. Automated quantification of roots using a simple image analyzer. Agron. J. 81:935-938.

Owenby, J.R., and D.S. Ezell. 1992. Monthly station normals of temperature, precipitation, and heating and cooling degree days 1961-1990. Climatography of the United States No. 81, U.S. Dep. of Commerce Nat. Oceanic and Atmospheric Admin., Asheville, N.C.

Troughton, A. 1957. The underground organs of herbage grasses. Commonwealth Bur. Pasture and Field Crops Bull. 44.

Weaver, J.E. 1954. North American prairie. Johnsen Pub. Co., Lincoln, Nebr. 